\title{
Effect of magnetic activity on plasma bubbles over equatorial and low-latitude regions in East Asia
}

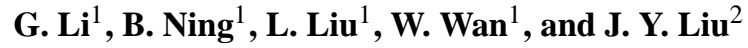 \\ ${ }^{1}$ Beijing National Observatory of Space Environment, Institute of Geology and Geophysics, Chinese Academy of Sciences, \\ Beijing, China \\ ${ }^{2}$ Institute of Space Science, National Central University, Chung-Li, Taiwan
}

Received: 3 April 2008 - Revised: 2 September 2008 - Accepted: 21 October 2008 - Published: 19 January 2009

\begin{abstract}
The dependence of plasma bubble occurrence in the eveningside ionosphere, with magnetic activity during the period years 2001-2004, is studied here based on the TEC observations gathered by ground-based GPS receivers which are located in the equatorial and low-latitude regions in East Asia. The observed plasma bubbles consist of the plasma-bubble events in the equatorial (stations GUAM, PIMO and KAYT), and low-latitude regions (stations WUHN, DAEJ and SHAO). It is shown that most equatorial plasma-bubble events commence at 20:00 LT, and may last for $>60 \mathrm{~min}$. The magnetic activity appears to suppress the generation of equatorial plasma bubbles with a time delay of more than $3 \mathrm{~h}(4-9 \mathrm{~h})$. While in the low-latitude regions, most plasma-bubble events commence at about 23:00 LT and last for $<45 \mathrm{~min}$. The best correlation between $K_{p}$ and lowlatitude plasma-bubble occurrence is found with an $8-9 \mathrm{~h}$ delay, a weak correlation exists for time delays of 6-7 h. This probably indicates that over $3 \mathrm{~h}$ delayed disturbance dynamo electric fields obviously inhibit the development of plasma bubbles in the pre-midnight sector.
\end{abstract}

Keywords. Ionosphere (Equatorial ionosphere; Ionospheric disturbances; Ionospheric irregularities)

\section{Introduction}

Plasma bubbles are plasma density depletions and accompanying plumes of irregularities that rise in altitude to extend to a wide band in latitude. These irregularities are formed in the post-sunset period due to the gravitational Rayleigh-Taylor (RT) instability processes operating on the steep upward gradient in the bottomside F-region. These are most frequently observed in the pre-midnight sector, as shown in the large

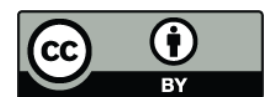

Correspondence to: $\mathrm{G} . \mathrm{Li}$ (gzlee@mail.iggcas.ac.cn) quantities of in-situ and ground-based data, such as a range spread echo in ionogram (Woodman and LaHoz, 1976), radio scintillation shown as rapid amplitude or phase fluctuations for the radio wave communication between space and ground (Basu et al., 1985), the pronounced density depletion in airglow (Kelley et al., 2002; Sahai et al., 2004), significant bite-outs in density from in-situ observation (Hysell and Burcham, 1998; Huang et al., 2002; Burke et al., 2004; $\mathrm{Su}$ et al., 2006), and their signatures in the magnetic field (Stolle et al., 2006). After sunset, the equatorial F-layer rises quickly to higher altitudes owing to the enhanced eastward electric field, which is known as the pre-reversal enhancement (PRE). When the F-layer has risen to an altitude where the ion-neutral collision frequency is small, the local RT instability becomes susceptible to triggering and the condition is favorable for the development of irregularities.

In addition to the effects of day-to-day variability, the equatorial electric fields could be affected by two main highlatitude sources during magnetic disturbances, namely the solar wind-magnetosphere dynamo (Senior and Blanc, 1984) and the ionospheric disturbance dynamo (Blanc and Richmond, 1980). The former is due to dynamic interactions between the solar wind and the magnetosphere that leads to changes in the polar cap potential causing prompt penetration of electric fields into low latitudes (Kelley et al., 1979; Fejer and Scherliess, 1997), and giving rise to perturbations in the zonal electric fields. The direct or prompt penetration electric fields are short-lived (1-2h) and propagate almost instantly to equatorial and low-latitudes (Fejer, 1991). Whereas, the later is due to global thermospheric circulation induced by joule heating at auroral latitudes that generates long-lived electric field disturbances at mid and low latitudes by ionospheric wind dynamo (Sherliess and Fejer, 1997). In the equatorial region, the neutral winds drive long-lived (several hours) electric fields, which are westward in the premidnight sector. According to Blanc and Richmond (1980), the delay time to the strongest disturbances in the equatorial

Published by Copernicus Publications on behalf of the European Geosciences Union. 
Table 1. GPS stations (station code, geographic longitude/latitude and magnetic latitude are listed).

\begin{tabular}{ccccc}
\hline $\begin{array}{c}\text { Station } \\
\text { code }\end{array}$ & Region & $\begin{array}{c}\text { Geographic } \\
\text { longitude }\end{array}$ & $\begin{array}{c}\text { Geographic } \\
\text { latitude }\end{array}$ & $\begin{array}{c}\text { Magnetic } \\
\text { latitude }\end{array}$ \\
\hline GUAM & & 144.9 & 13.6 & 5.2 \\
PIMO & Equatorial latitude & 121.1 & 14.6 & 4.5 \\
KAYT & & 121.0 & 14.0 & 3.9 \\
& & 114.3 & 30.5 & 20.2 \\
WUHN & & 127.4 & 36.4 & 26.5 \\
DAEJ & Low latitude & 121.2 & 31.1 & 21.0 \\
SHAO & & & & \\
\hline
\end{tabular}

region is $9 \mathrm{~h}$, but studies on radar measurements suggest delays of only a few hours (Fejer and Scherliess, 1995). Taking into consideration the added penetration or dynamo electric field tends to enhance or diminish the effect of PRE near sunset, and determines the favorable or unfavorable conditions for the development of plasma bubbles, many authors have made efforts to examine the influence of magnetic activity on the occurrence of ionophseric irregularities (e.g. Singh et al., 1997a; Martinis et al., 2005; Tulasi Ram et al., 2008).

Earlier studies of the effects of geomagnetic storms on the development or inhibition of ionospheric irregularities have shown that there is a general consensus that magnetic activity tends to suppress the generations of spread-F or plasma bubbles in the pre-midnight period, whereas the possibility of observing spread-F or plasma bubbles during the postmidnight period increases with magnetic activity. The enhancement or suppression of pre-midnight equatorial spread$F$ depends on the relative contributions from the prompt penetration and ionospheric disturbance dynamo induced electric field disturbances with respect to local time effects during the geomagnetic storms (Martinis et al., 2005; Basu et al., 2007). By analyzing the universal time (UT) of the storm's peak effect $\left(\left|D_{s t}\right|\right)$, Aarons (1991) explored the irregularities occurrence versus longitude and storm time. Basu et al. (2001) related the occurrence of strong irregularities with rate of change of $D_{s t}$ larger than $-50 \mathrm{nT} / \mathrm{h}$. Using large numbers of scanning photometers and imagers data of the atomic oxygen $630 \mathrm{~nm}$ nocturnal airglow, Sobral et al. (2002) analyzed the $K_{p}$ index and plasma bubbles and found a correlation existing between large $K_{p}$ values in the 19:00-21:00 LT period and the occurrence of irregularities. Based on the Dynamics Explorer (DE) 2 satellite observations from $\mathrm{Au}-$ gust 1981 to February 1983, Palmroth et al. (2000) investigated the occurrence of equatorial plasma bubbles and found that magnetic activity appears to suppress the generation of eveningside plasma bubbles with a delay of $2-3 \mathrm{~h}$. However, as Palmroth et al. (2000) suggested, owing to the effects that the satellite can not continuously position - when the DE 2 observed a plasma bubble - the bubble probably had been generated a few hours before it was observed by the satellite.
Therefore, an uncertainty on the exact time delays probably exists.

Besides space-based satellite observations, the groundbased GPS receivers provide a new observational technique for investigating the effect of magnetic activity on plasma bubbles. They measure total electron content (TEC) continuously with little lack of data. Since plasma bubbles can cause TEC fluctuations when the satellite beacon crosses the density depletions, Rama Rao et al. (2006) found that the TEC depletion can reach 15 TEC units. Beach et al. (1999) reported that the small scale fluctuation of TEC with a five minute period has larger amplitude inside of plasma bubbles, while outside of the plasma bubble, the amplitude is small. Therefore it is a strong tool to obtain the first occurrence time and duration of plasma-bubble events. In this paper, we investigate the effect of magnetic activity on plasma bubbles by utilizing measurements of ground-based GPS receivers in years 2001-2004. Exact time delays of $K_{p}$ index, inhibiting the generation of plasma bubbles have been obtained.

\section{Data selection and processing}

The six ground-based GPS receivers used here were located in East Asia, as shown in Table 1. These six were chosen because they extend both equatorial and low-latitude near the same longitudinal meridian $120^{\circ} \mathrm{E}$ (except GUAM), and the data were available during the period years 2001-2004.

Using the worldwide GPS network, Pi et al. (1997) monitored, firstly, the global ionospheric irregularities. To identify and to statistically present the smaller scale irregularities, they defined a rate of TEC index (ROTI) based on the standard deviation of ROT within five minutes, and suggested that ROTI can be used to detect the presence of ionospheric irregularities. The index is often used to investigate ionospheric fluctuations (Bhattacharyya et al., 2000). Recently, using ROTI derived from the GPS TEC data obtained from IGS, JAMSTEC and SOPAC networks, Nishioka et al. (2007) investigated the characteristic of global-scale plasma-bubble occurrence rates. Taking into account the different noise level of ROTI for each GPS receivers, Nishioka et al. (2007) used the difference of the day time ROTI $\left(R_{\text {day }}\right)$ and the evening ROTI $\left(R_{\mathrm{ev}}\right)$ for detecting the occurrence of plasma bubbles, and found that most of $R_{\mathrm{ev}}-R_{\text {day }}$ were between $-0.05 \mathrm{TECU} / \mathrm{min}$ and $0.05 \mathrm{TECU} / \mathrm{min}$. A threshold value of $0.075 \mathrm{TECU} / \mathrm{min}$ was proposed.

Here we shall use the difference value of $R_{\mathrm{ev}}-R_{\text {day }}$ for detecting the occurrence of plasma bubbles. $R_{\mathrm{ev}}$ means ROTI value within the period 18:00-06:00 LT for a single GPS satellite, and $R_{\text {day }}$ is the mean value of ROTI within the period 11:00-14:00 LT for all satellites. In the following sections, ROTI means the difference value of $R_{\mathrm{ev}}-R_{\mathrm{day}}$, and the GPS satellite elevation angle is confined to greater than $30^{\circ}$. Experiments indicate that the threshold of $0.075 \mathrm{TECU} / \mathrm{min}$ with elevation angle $30^{\circ}$ is appropriate for identifying plasma 


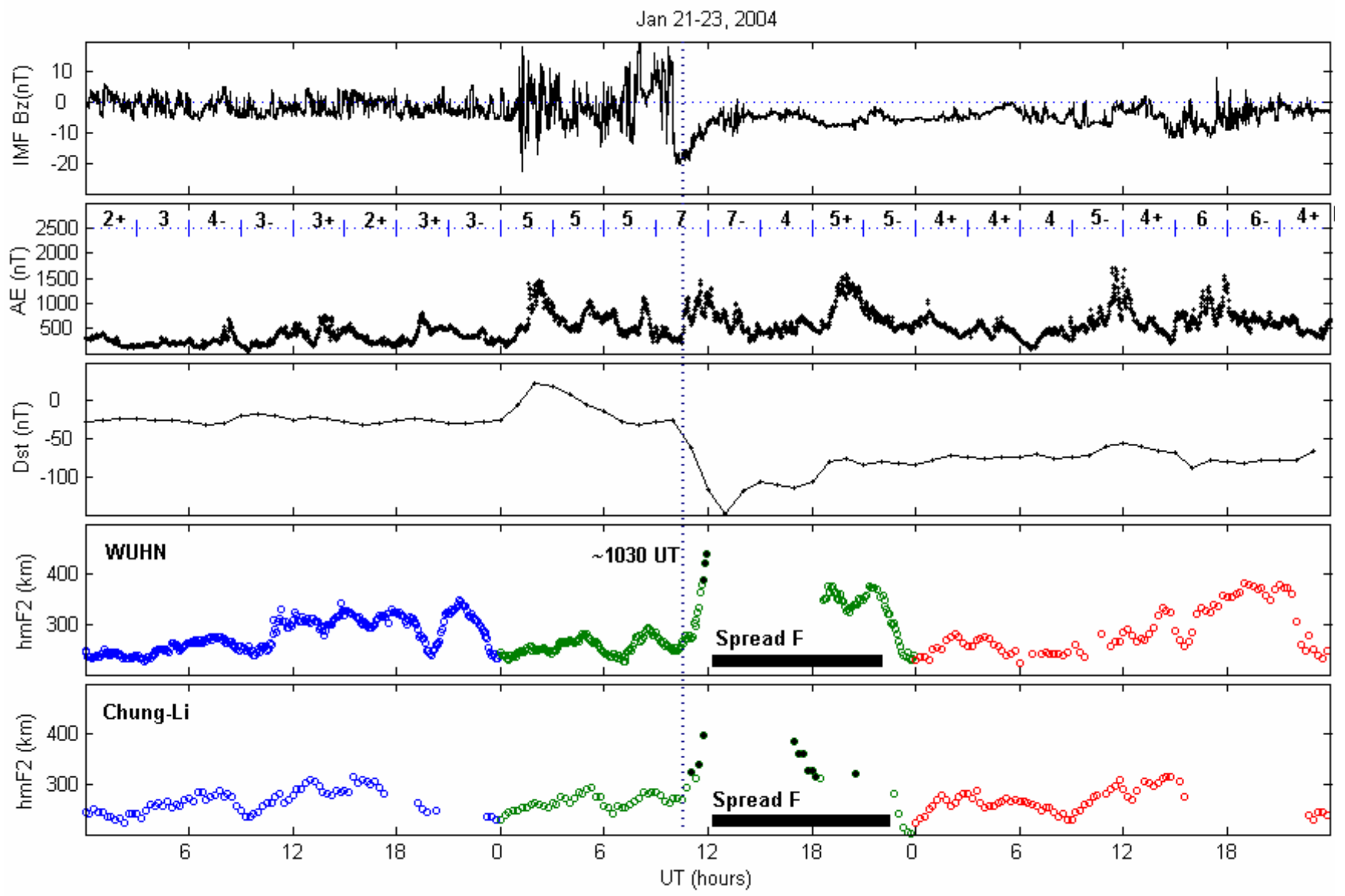

Fig. 1. IMF $B_{z}, \mathrm{AE}, K_{p}$ and $D_{s t}$ indices, and $h m \mathrm{~F} 2$ obtained from Wuhan and Chungli during 21-23 January 2004. The horizontal thick lines marked in the bottom two panels indicate the times when the spread-F irregularities are detected.

bubble occurrence frequency. The determination of plasmabubble occurrence frequency is based on whether or not plasma-bubble signatures were detected on a given night. If there are two ROTI values greater than $0.075 \mathrm{TECU} / \mathrm{min}$ within one hour for a single GPS satellite, it was decided that plasma bubbles were present on that day. And the time will be attributed to the first occurrence time of plasma-bubble events. The decision that plasma bubbles were absent has been taken on the basis that no plasma-bubble signature was apparent all night. Therefore the observational data for the entire night is required.

\section{Results and discussion}

\subsection{Example of plasma-bubble events}

Figures 1-3 present an example of plasma-bubble events which occurred over equatorial and low-latitude regions in East Asia, during the magnetic storm of 22 January 2004. As shown in the top three panels of Fig. 1, the variation of interplanetary magnetic field (IMF $B_{z}$ ), AE, $K_{p}$ in- dex and $D_{s t}$ index are depicted, respectively, during 2123 January 2004. On 22 January, the IMF $B_{z}$ turned southward around 09:57 UT and showed a strong negative component of $-20 \mathrm{nT}$ at 10:07 UT. During the same time, the $D_{s t}$ value started decreasing and attained the lowest value of $-150 \mathrm{nT}$ at 13:00 UT. The $K_{p}$ index varied up to 7 . It is seen from the bottom two panels that the peak height of F-layer obtained from low-latitude stations WUHN $\left(114.3^{\circ} \mathrm{E} / 30.5^{\circ} \mathrm{N}\right.$; Mag., 20.2 $\left.\mathrm{N}\right)$ and Chung$\mathrm{Li}\left(121.1^{\circ} \mathrm{E} / 24.9^{\circ} \mathrm{N}\right.$; Mag., $\left.14.8^{\circ} \mathrm{N}\right)$ increased rapidly to over $400 \mathrm{~km}$ during the period 10:30-12:00 UT, which corresponds to local postsunset hours (18:30-20:00 LT) over the two stations. The sudden simultaneous turn in IMF $B_{z}$ and increase in $h m \mathrm{~F} 2$ possibly suggests that there is a prompt penetration of eastward electric fields into low latitudes that augmented the normal F-region dynamo induced PRE, thereby lifting the F-layer to higher altitudes and creating conditions favorable for the development of spread-F. And then intense spread-F irregularities have been observed as shown in the bottom two panels, marked by horizontal thick lines. 

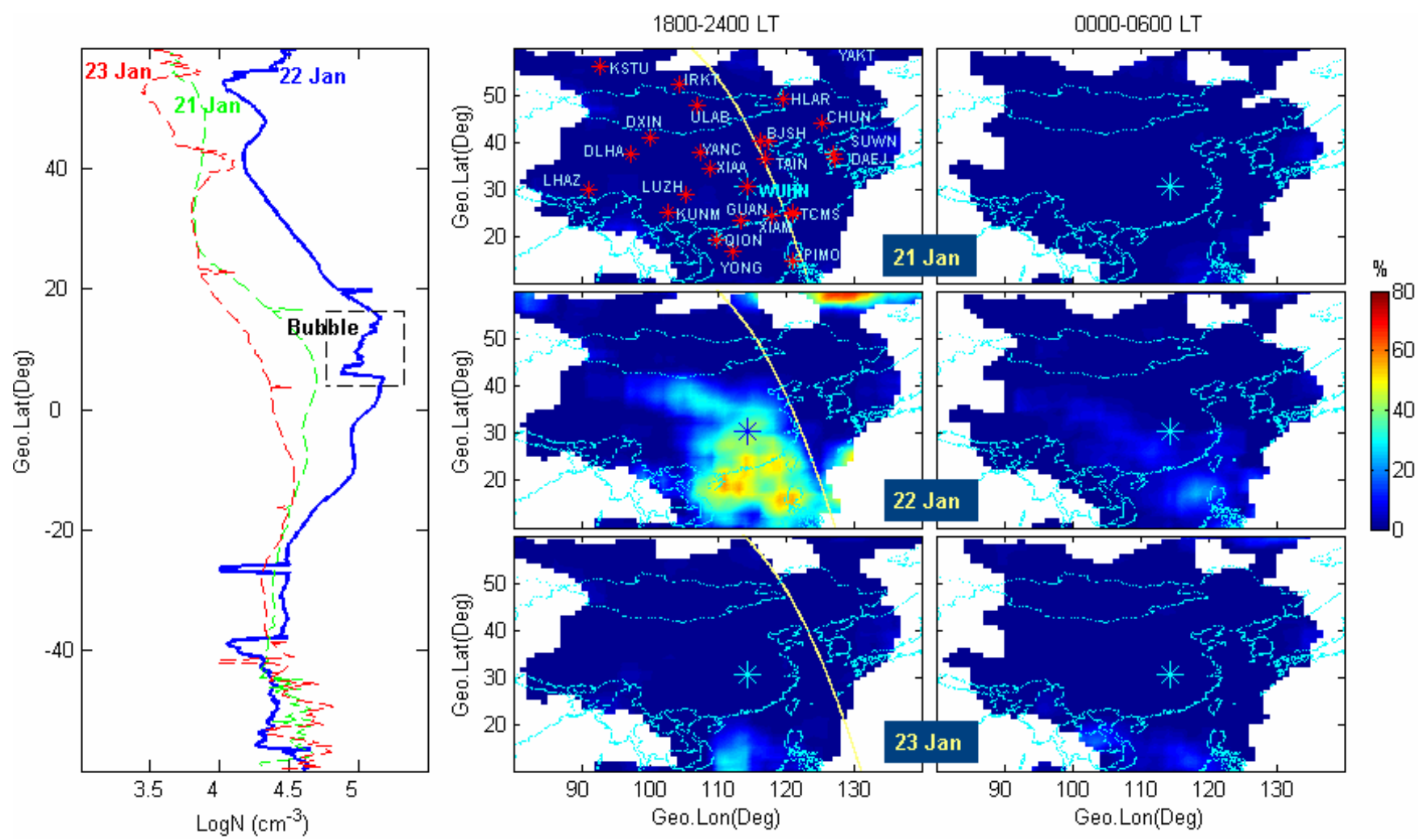

Fig. 2. In situ ion density measurements and plasma-bubble occurrence probability during 21-23 January 2004. The left panel shows the measurements of ion density from DMSP F15 near 21:30 LT (F15 passes the equator from the south to the north), and the middle and right panels show the map of percentage occurrence of plasma bubbles for pre- and post-midnight (the yellow lines show the F15 orbits, the white areas in the map represent regions of data lack, and the GPS receivers used in this figure are labeled as red asterisks).

The plasma-bubble occurrence rates during this storm period are also shown in Fig. 2. The left panel of Fig. 2 shows the DMSP-F15 plasma density measurements. The satellite is a three-axis stabilized spacecraft that flies in Sunsynchronous circular polar orbits at $\sim 840 \mathrm{~km}$ altitude. The orbital planes are near 21:30-09:30 geographic LT meridians with the ascending nodes on the duskside of the earth. The plasma data used here are from the observations of Special Sensor-Ions, Electrons, and Scintillation (SSIES) packages on board the satellite (Rich and Hairston, 1994). We can see from the panel that the apparent plasma depletions (indicated by the rectangle) were observed on the storm day. Based on the GPS networks in the China and adjacent regions, a method (within a square grid of $1^{\circ}$ in geographic longitude and latitude, the number of $\mathrm{ROTI} \geq 0.075$ is divided by the total number of ROTI to obtain the plasma-bubble occurrence rate in that square area at pre- and post-midnight, and then obtain the grid map of low-latitude plasma-bubble occurrence rates) was employed to yield the plasma-bubble occurrence map, as presented in the middle and right panels. The middle two panels of Fig. 2 on the storm day show that plasma bubbles were observed at a wide latitude region, and were found to extend to post-midnight sector.
Figure 3 presents the results of ionospheric scintillations and irregularities observed at WUHN. The scintillation measurement was performed using the GPS Ionospheric scintillation/TEC Monitor (GISTM), model GSV4004. The system is NovAtel's Euro4 dual-frequency receiver version of the OEM4 card with special firmware, which was especially developed to maintain lock even under strong scintillation conditions (Van Dierendonck et al., 1993). A close comparison of amplitude scintillation index S4 and ROTI for all satellites indicates that the enhanced scintillation structures correspond well with fluctuations of ROTI. From the figure, we can note that plasma bubbles can be identified with the above presented threshold value, $0.075 \mathrm{TECU} / \mathrm{min}$ for ROTI. The first occurrence of plasma-bubble events on this day is 12:00 UT, and the maximum duration is about $3 \mathrm{~h}$.

\subsection{Statistical results}

The local time distribution of the first occurrence of the plasma-bubble events, and duration distribution at equatorial and low latitudes are plotted in Figs. 4 and 5, respectively. They display that most equatorial plasma bubbles start growing at 20:00 LT, and may last for $>60 \mathrm{~min}$. However, the 

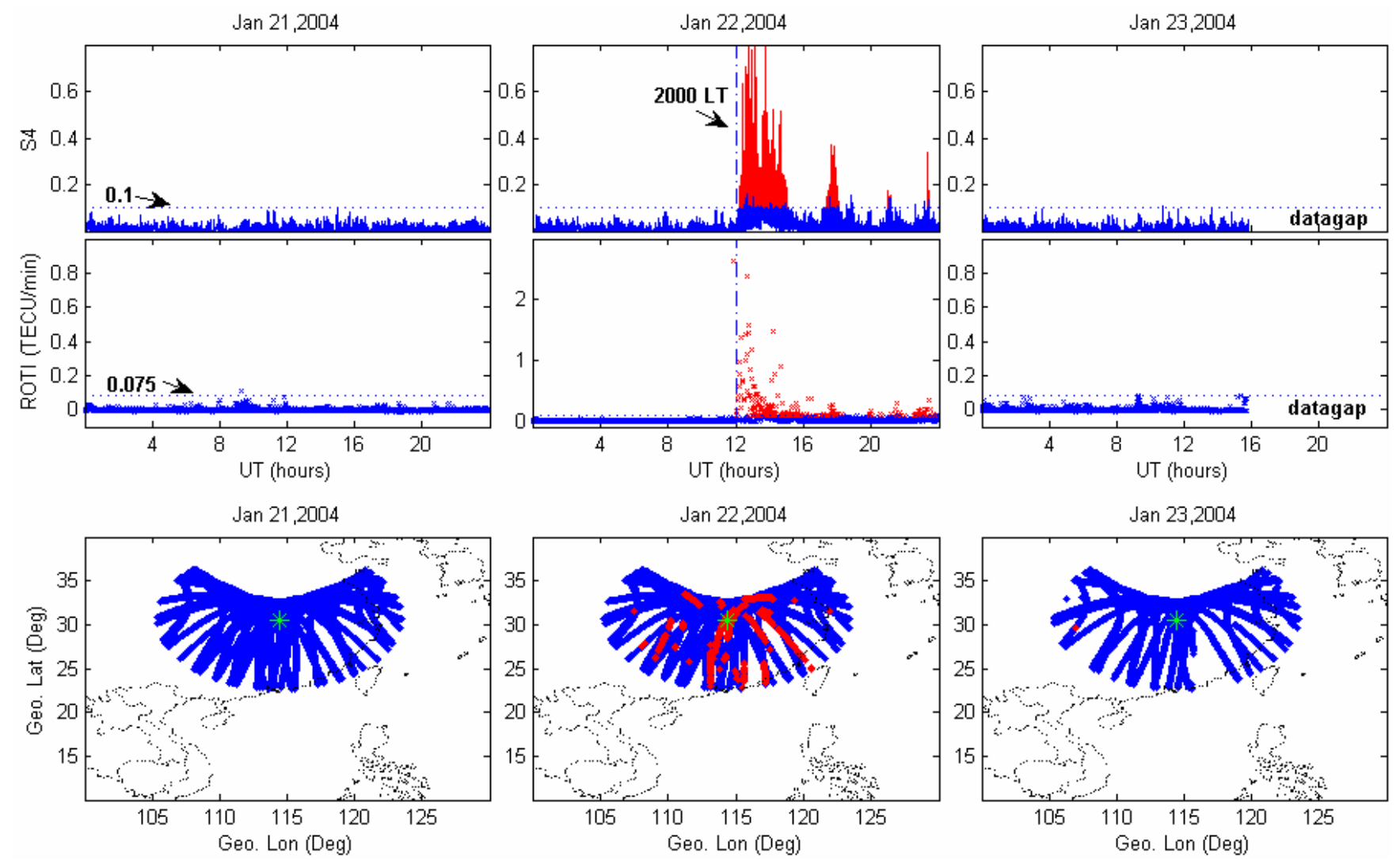

Fig. 3. GPS ionospheric scintillations/irregularities observed at WUHN on 21-23 January 2004. (top) Amplitude scintillation index S4 ( $\mathrm{S} 4 \geq 0.1$ marked as red color) for all satellites. (middle) Rate of TEC index (ROTI $>0.075$ marked as red color) for all satellites. (bottom) Maps of GPS satellite tracks in the $400 \mathrm{~km}$ altitude (red traces represent the scintillation occurrence).

dependence of the first occurrence of low latitude plasma bubbles on local time is at its maximum at 23:00 LT, and most plasma bubble events last for $<45 \mathrm{~min}$. It indicates that the duration of plasma bubbles becomes greater as one approaches the equator (Chandra et al., 1993; Singh et al., 2004). In addition, a time delay of about $3 \mathrm{~h}$ exists between the first occurrence time of equatorial and low-latitude plasma bubbles. Although the fact that equatorial plasma bubbles can extend to a wide band in latitude along the magnetic field lines, and the low-latitude plasma bubble occurrence can be influenced by equatorial plasma bubble development, the time delay of $3 \mathrm{~h}$ seems to be too long for an equatorial plasma bubble to elongate along the magnetic field lines to low latitudes. It probably indicates that these low latitude bubbles are locally generated plasma bubbles.

Taking into account that most plasma-bubble events commence at pre-midnight, and the sample for post-midnight is not enough to perform a statistical analysis, especially for equatorial regions, in this paper we limit our attention to the dependence of plasma bubble occurrence for different magnetic activity conditions in the pre-midnight sector (18:0024:00 LT). Figures 6 and 7 present the results for eveningside at PIMO and WUHN, respectively (the results at other stations are similar). The $K_{p}$ index delayed by $4(9)$ h is used to characterize plasma bubble dependence on magnetic activity, where a 4-h (9-h) delayed $K_{p}$ means the $K_{p}$ value 4 (9) h before the hour of the first occurrence time of plasma bubbles. Figure 6a displays the distribution of 4-h delayed $K_{p}$ values during all days with data collected. Figure $6 \mathrm{~b}$ shows the number of days with plasma-bubble events, and Fig. $6 \mathrm{c}$ is the normalized plasma bubble occurrence rate, obtained by dividing Fig. 6a by Fig. 6b. From the last bin of Fig. 6a and $\mathrm{b}$ we can note that the number of nights for data collected and bubble observations are 170 and 46, respectively. These numbers are significant enough to investigate the effects of magnetic activity on plasma bubble occurrence. As shown in Fig. 6c, the occurrence distribution decreases with increasing magnetic activity. On the basis of the statistics presented by Figs. 6 and 7, we conclude that the magnetic activity decreases the number of bubbles in the pre-midnight sector at PIMO (WUHN) with a delay time of 4 (9) $\mathrm{h}$.

The plasma bubble dependence on $K_{p}$ with other time delays was also studied. Figures 8 and 9 show the normalized plasma bubble occurrence rates as functions of $0-9 \mathrm{~h}$ delayed $K_{p}$ for the equatorial station PIMO and low latitude station WUHN. The panels have been obtained using the same way 

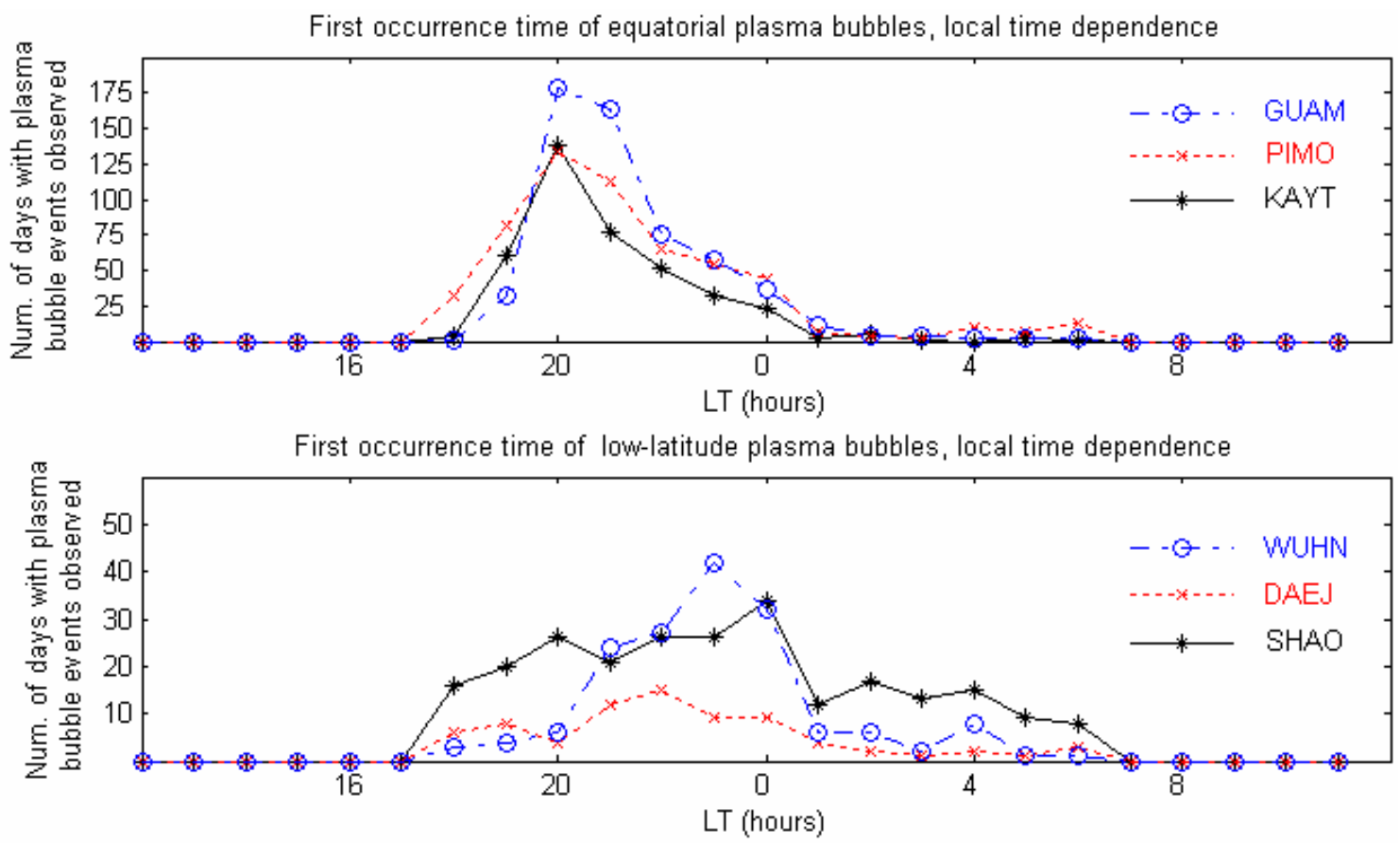

Fig. 4. Number of days with the first occurrence time of plasma bubble events at each local time sector.
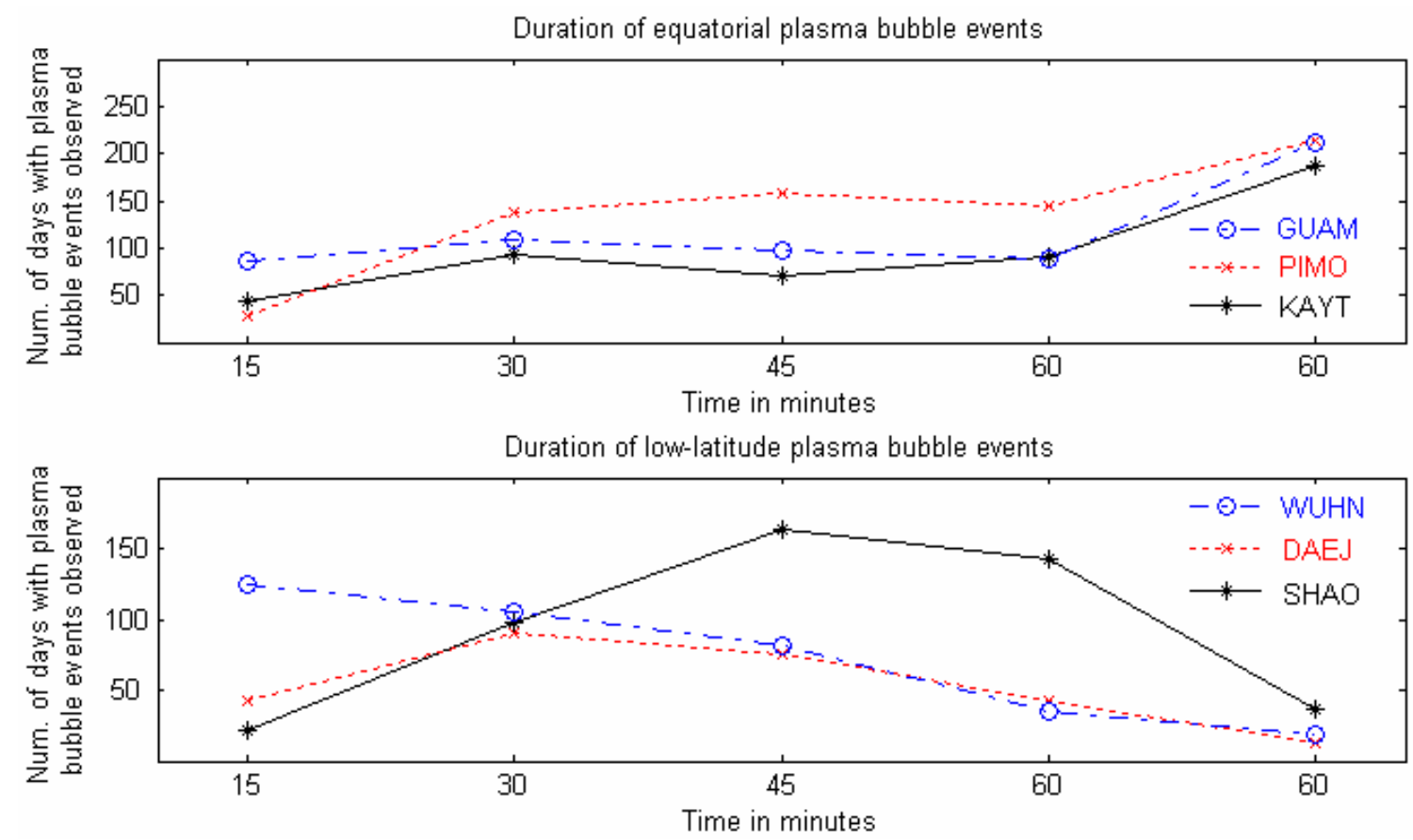

Fig. 5. Distribution of duration of plasma bubble events.

as Fig. 6c. Notice first that at PIMO, the probability of observing plasma bubbles is independent on magnetic activity for $0-2 \mathrm{~h}$ delay. For more than $3 \mathrm{~h}$ (4-9 h) delay, the plasma bubble occurrence is best suppressed by magnetic activity. The observations presented here indicate that the best inverse correlation between magnetic activity and plasma bubbles appears at over $3 \mathrm{~h}$ delay at equatorial latitudes. This supports the in-situ observational results reported by Palmroth et al. (2000). By using DE 2 plasma density observations, they reported the best inverse correlation appeared at 2-3 h delay, 


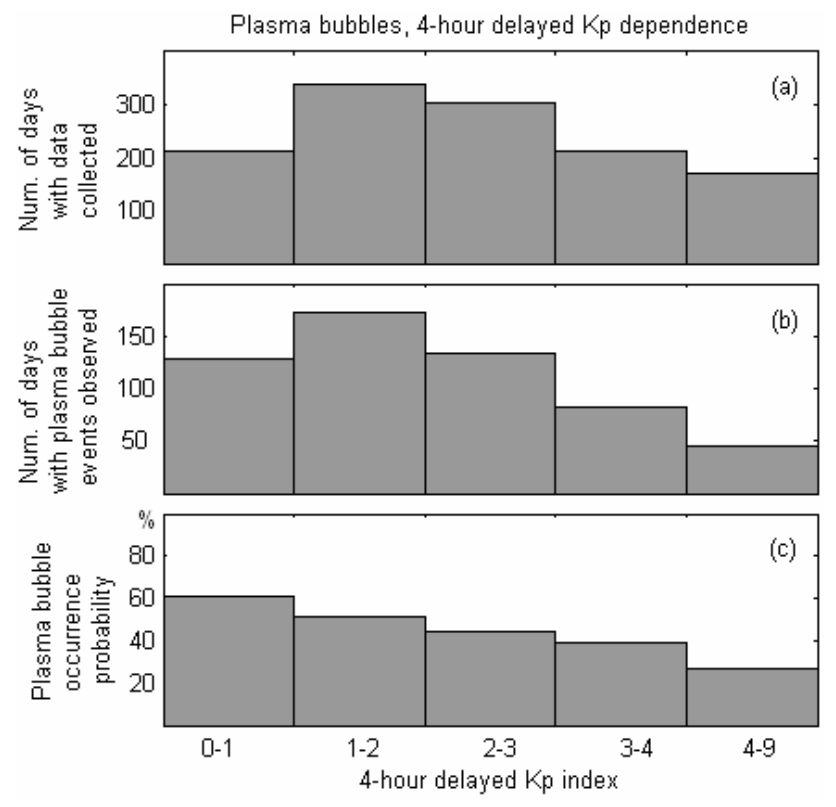

Fig. 6. (a) Number of 4-h delayed $K_{p}$ indices during all days with data collected. (b) Number of days with plasma bubble events plotted against 4-h delayed $K_{p}$ index. (c) Plasma bubble occurrence probability versus 4 -h delayed $K_{p}$ index. (PIMO observations).

however with time delays of 4-8 h, only weak inverse correlation is seen. From this figure, we can note that the inverse correlation is also presented for $4-9 \mathrm{~h}$ delayed $K_{p}$. On the other hand, Fig. 9 shows the results obtained at WUHN. The best correlation between bubble occurrence and magnetic activity is seen with $8-9 \mathrm{~h}$ delayed $K_{p}$. Weak correlation is observed with time delays 6-7 h, whereas for time delays 0 $5 \mathrm{~h}$, the magnetic activity does not affect the probability of observing plasma bubbles. This is consistent with equatorial observational results since there is a time delay about $3 \mathrm{~h}$ between the first occurrence of equatorial and low-latitude plasma bubbles.

\subsection{Discussion}

It has been suggested that the plasma bubble development or inhibition conditions associated with magnetic activity can arise from (1) prompt penetration of an electric field that occurs over equatorial latitudes in association with magnetic disturbances phases, and especially with the build up, growth and decay phase of auroral substorms, and (2) delayed effects, due to disturbance of thermosphere global circulation resulting from magnetospheric energy deposition at auroral latitude, that involves a few hours of delay with respect to the high latitude disturbance onsets. The prompt penetrating electric fields can have significant amplitudes but only for periods of about $1-2 \mathrm{~h}$. The rapid change of $D_{s t}$ often signifies the prompt penetration of high latitude electric fields (e.g. Basu et al., 2005; Li et al., 2008). Returning to Fig. 1, a

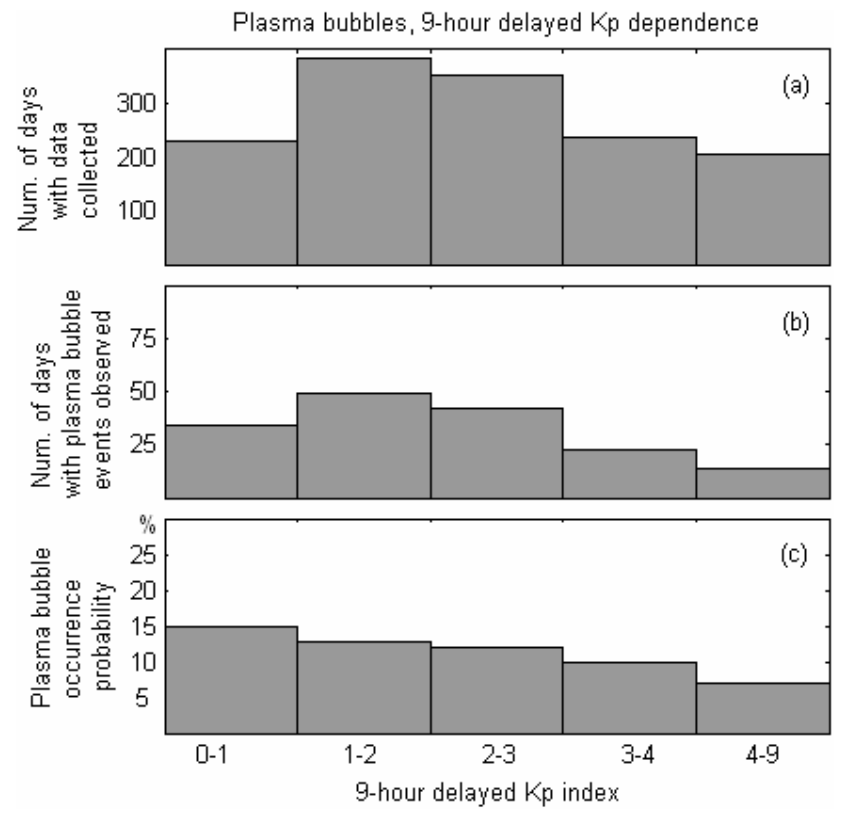

Fig. 7. Same as Fig. 6 for WUHN observations.

rate of change of $D_{s t}$ reached $-53 \mathrm{nT} / \mathrm{h}$ at 11:00 UT, having a good time correlation with the simultaneous uplift of the F-region at the two ionosonde stations. It can be concluded that a prompt penetration of magnetospheric eastward electric field caused the postsunset ionospheric disturbances observed at the two stations. Via the $\boldsymbol{E} \times \boldsymbol{B}$ drift, the enhanced eastward electric fields lift the F-layer to a higher altitude near postsunset, where the RT mode becomes unstable, and then forms plasma bubbles and spread-F irregularities. This further confirms the development of spread-F irregularities or plasma bubbles due to the penetration of eastward electric fields into low latitudes during postsunset hours.

With increasing magnetic activity, Singh et al. (1997b) reported the probability of observing equatorial F-region plasma bubbles decreasing in the pre-midnight sector, and a westward electric field buildup in the pre-midnight sector a few hours after the magnetic disturbances was thought of as a reason. The disturbance dynamo effects must be superimposed upon the normal dynamo effects, which remain active during magnetic disturbances. Blanc and Richmond (1980) suggest that the delay time between the onset of a substorm and strongest electric fields in equatorial region is $9 \mathrm{~h}$, whereas Fejer and Scherliess (1995) suggest a time delay of only a few hours. The observations presented here reveal that the best inverse correlation between magnetic activity and bubble occurrence rate appears at $4-9 \mathrm{~h}$ delay. For time delays of $0-2 \mathrm{~h}$, the statistical occurrence rates of plasma bubbles are independent of magnetic activity.

The present statistical result agrees with the effect of disturbance dynamo electric field for the evening sector based on Jicamarca vertical drift data (Scherliess and Fejer, 1997). 

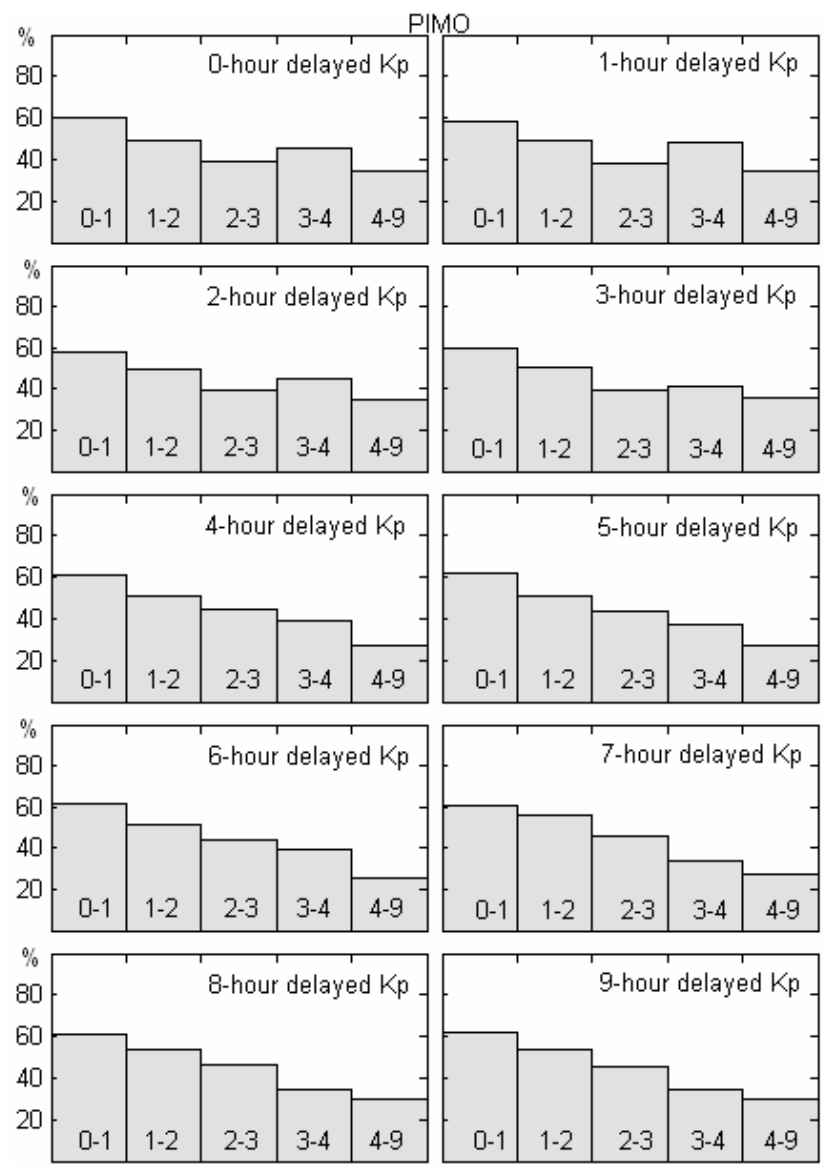

Fig. 8. Plasma bubble occurrence probability versus $0-9 \mathrm{~h}$ delayed $K_{p}$ index (PIMO observations).

Such effects, in fact, occur through the control of magnetic activity on the PRE that is basically responsible for the postsunset plasma bubble development. The results of Fig. 4 show that most of the equatorial plasma bubble events commencing at 20:00 LT, that is, for more than $3 \mathrm{~h}$ delayed $K_{p}$ (4-9 h), the magnetic activity occurring at the local time period 11:00-16:00 LT. These results are consistent with earlier studies that the disturbance dynamo electric fields arising from such activities produce negative effects on PRE, and then inhibit the plasma bubble occurrence.

\section{Conclusions}

Using the ground-based GPS receivers, a detailed study has been carried out on the effects of magnetic activity on plasma bubble occurrence over equatorial and low-latitude regions in East Asia during the years 2001-2004. The results have shown that most equatorial plasma bubble events commence at 20:00 LT, and may last for $>60 \mathrm{~min}$. Magnetic activity appears to suppress the generation of equatorial plasma bubbles with a time delay of more than $3 \mathrm{~h}(4-9 \mathrm{~h})$. While dur-
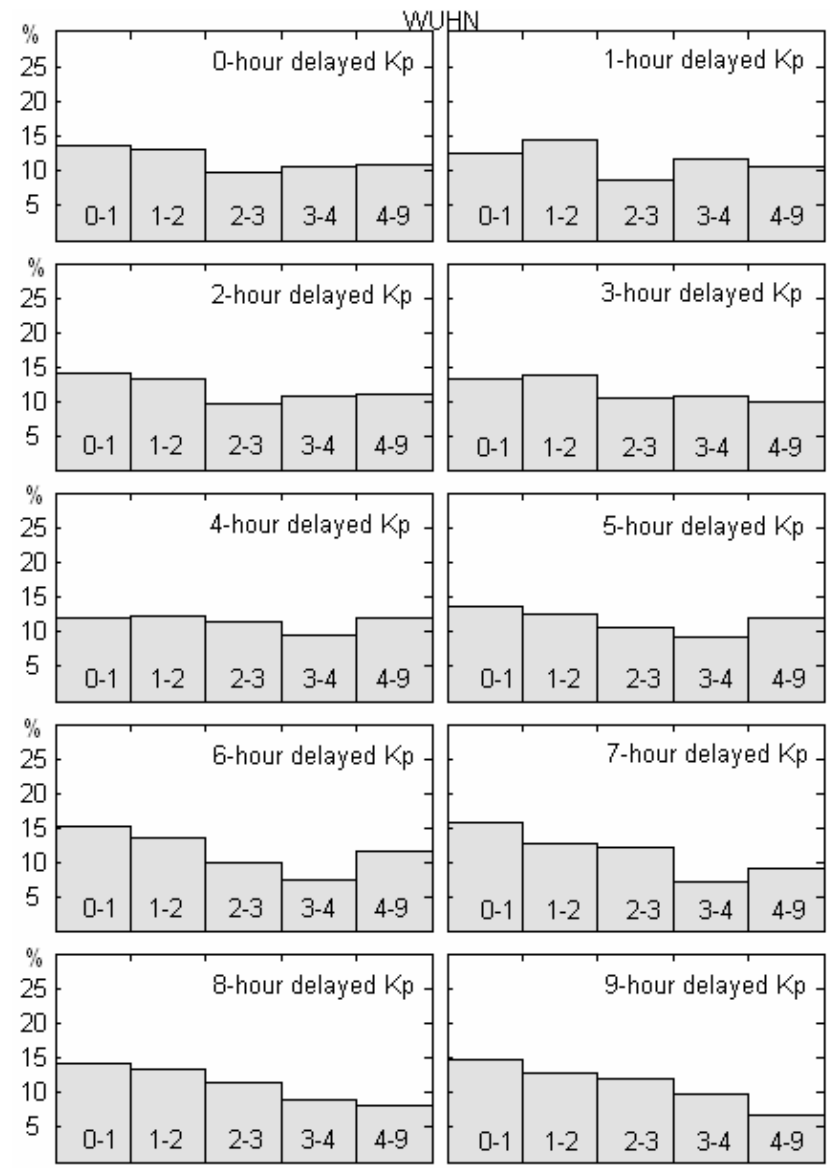

Fig. 9. Same as Fig. 8 for WUHN observations.

ing low-latitude regions, most plasma bubble events commence at about 23:00 LT and last for $<45 \mathrm{~min}$. The best correlation between $K_{p}$ and low-latitude plasma bubble occurrence is found with $8-9 \mathrm{~h}$ delay, a weak correlation exists for time delays of $6-7 \mathrm{~h}$. This is consistent with equatorial observational results since there is a time delay about $3 \mathrm{~h}$ between the first occurrence time of equatorial and low-latitude plasma bubbles. It appears that over $3 \mathrm{~h}$ delayed disturbance dynamo electric fields obviously inhibit the development of pre-midnight plasma bubbles in this region.

Acknowledgements. This work was supported by National Natural Science Foundation of China (40774091, 40574072, 40725014) and the the National Important Basic Research Project (2006CB806306). The authors thank the referees for their valuable suggestions to improve the paper. The authors acknowledge UT-Dallas for providing the DMSP datasets, and also IGS and CDAWeb for providing the GPS and IMF $B_{z}, K_{p}$, AE and $D_{s t}$ datasets, respectively.

Topical Editor M. Pinnock thanks P. V. S. Rama Rao and another anonymous referee for their help in evaluating this paper. 


\section{References}

Aarons, J.: The role of the ring current in the generation or inhibition of equatorial F-layer irregularities during magnetic storms, Radio Sci., 26, 1131-1149, 1991.

Basu, S. and Basu, S.: Equatorial scintillations: advances since ISEA-6, J. Atmos. Solar Terr. Phys., 47, 753-768, 1985.

Basu, Su., Basu, S., Valladares, C. E., Yeh, H.-C., Su, S.-Y., Mackenzie, E., Sultan, P. J., Aarons, J., Rich, F. J., Doherty, P., Groves, K. M., and Bullett, T. W.: Ionospheric effects of major magnetic storms during the international space weather period of September and October 1999: GPS observations, VHF/UHF scintillations, and in situ density structures at middle and equatorial latitudes, J. Geophys. Res., 106(A12), 30 389-30 414, 2001.

Basu, S., Basu, Su., Groves, K. M., MacKenzie, E., Keskinen, M. J., and Rich, F. J.: Near-simultaneous plasma structuring in the midlatitude and equatorial ionosphere during magnetic suprestorms, Geophys. Res. Lett., 32, L12S05, doi:10.1029/2004GL021678, 2005.

Basu, S., Basu, Su., Rich, F. J., Groves, K. M., MacKenzie, E., Coker, C., Sahai, Y., Fagundes, P. R., and Becker-Guedes, F.: Response of the equatorial ionosphere at dusk to penetration electric fields during intense magnetic storms, J. Geophys. Res., 112, A08308, doi:10.1029/2006JA012192, 2007.

Beach, T. L. and Kintner, P. M.: Simultaneous Global Positioning System observations of equatorial scintillations and total electron content fluctuations, J. Geophys. Res., 104(A10), 22 553-22 566, doi:10.1029/1999JA900220, 1999.

Bhattacharyya, A., Beach, T. L., Basu, S., and Kinter, P. M.: Nighttime equatorial ionosphere: GPS scintillations and differential carrier phase fluctuations, Radio Sci., 35(1), 209-234, 2000.

Blanc, M. and Richmond, A. D.: The ionospheric disturbance dynamo, J. Geophys. Res., 85(A4), 1669-1686, 1980.

Burke, B. J., Gentile, L. C., Huang, C., Valladares, C. E., and $\mathrm{Su}, \mathrm{S}$. Y.: Longitudinal variability of equatorial plasma bubbles observed by DMSP and ROCSAT-1, J. Geophys. Res., 109, A12301, doi:10.1029/2004JA010583, 2004.

Chandra, H., Vyas, G. D., Rao, D. R. K., et al.: Coordinated multistation VHF scintillation observations in India during MarchApril 1991, Ind. J. Radio Space Phys., 22, 69-81, 1993.

Fejer, B. G.: Low latitude electrodynamic plasma drifts: A review, J. Atmos. Terr. Phys., 53, 677-693, 1991.

Fejer, B. G. and Scherliess, L.: Time dependent response of equatorial electric fields to magnetospheric disturbances, Geophys. Res. Lett., 22, 851-854, 1995.

Fejer, B. G. and Scherliess, L.: Empirical models of storm time equatorial zonal electric fields, J. Geophys. Res., 102, $24047-$ 24 056, 1997.

Huang, C. Y., Burke, W. H., Machuzak, J. S., Gentile, L. C., and Sultan, P. J.: Equatorial plasma bubbles observed by DMSP satellites during a full solar cycle: Toward a global climatology, J. Geophys. Res., 107(A12), 1434, doi:10.1029/2002JA009452, 2002.

Hysell, D. L. and Burcham, J. D.: JULIA radar studies of equatorial spread F, J. Geophys. Res., 103(A12), 29 155-29 167, 1998.

Kelley, M. C., Fejer, B., and Gonzales, C.: An explanation for anomalous equatorial ionospheric electric fields associated with a northward turning of the interplanetary magnetic field, Geophys. Res. Lett., 6(4), 301-304, 1979.

Kelley, M. C., Makela, J. J., Ledvina, B. M., and Kintner, P. M.:
Observations of equatorial spread-F from Haleakala, Hawaii, Geophys. Res. Lett., 29(20), 2003, doi:10.1029/2002GL015509, 2002.

Li, G., Ning, B., Zhao, B., Liu, L., Liu, J. Y., and Yumoto, K.: Effects of geomagnetic storm on GPS ionospheric scintillations at Sanya, J. Atmos. Solar Terr. Phys., 70, 1034-1045, 2008.

Martinis, C. R., Mendillo, M. J., and Aarons, J.: Toward a synthesis of equatorial spread $\mathrm{F}$ onset and suppression during geomagnetic storms, J. Geophys. Res., 110, A07306, doi:10.1029/2003JA010362, 2005.

Nishioka, M., Saito, A., and Tsugawa, T.: Occurrence characteristics of plasma bubble derived from global ground-based GPS receiver networks, J. Geophys. Res., 113, A05301, doi:10.1029/2007JA012605, 2007.

Palmroth, M., Laakso, H., Fejer, B. G., and Pfaff Jr., R. F.: DE 2 observations of morningside and eveningside plasma density depletions in the equatorial ionosphere, J. Geophys. Res., 105(A8), 18 429-18 442, 2000.

Pi, X., Mannucci, A. J., Lindqwister, U. J., and Ho, C. M.: Monitoring of global ionospheric irregularities using the worldwide GPS network, Geophys. Res. Lett., 24(18), 2283-2286, 1997.

Tulasi Ram, S., Rama Rao, P. V. S., Prasad, D. S. V. V. D., Niranjan, K., Gopi Krishna, S., Sridharan, R., and Ravindran, S.: Local time dependent response of postsunset ESF during geomagnetic storms, J. Geophys. Res., 113, A07310, doi:10.1029/2007JA012922, 2008.

Rama Rao, P. V. S., Gopi Krishna, S., Niranjan, K., and Prasad, D. S. V. V. D.: Study of spatial and temporal characteristics of Lband scintillations over the Indian low-latitude region and their possible effects on GPS navigation, Ann. Geophys., 25, 15671580, 2006, http://www.ann-geophys.net/25/1567/2006/.

Rich, F. J. and Hairston, M.: Large-scale convection patterns observed by DMSP, J. Geophys. Res., 99(A3), 3827-3844, 1994.

Sahai, Y., Fagundes, P. R., Abalde, J. R., Pimenta, A. A., Bittencourt, J. A., Otsuka, Y., and Rios, V. H.: Generation of largescale equatorial F-region plasma depletions during low range spread-F season, Ann. Geophys., 22, 15-23, 2004, http://www.ann-geophys.net/22/15/2004/.

Scherliess, L. and Fejer, B. G.: Storm time dependence of equatorial disturbance dynamo zonal electric fields, J. Geophys. Res., 102, 24 037-24 046, 1997.

Senior, C. and Blanc, M.: On the control of magnetospheric convection by the spatial distribution of ionospheric conductivities, J. Geophys. Res., 89, 261-284, 1984.

Singh, R. P., Patel, R. P., and Singh, A. K.: Effect of solar and magnetic activity on VHF scintillations near the equatorial anomaly crest, Ann. Geophys., 22, 2849-2860, 2004, http://www.ann-geophys.net/22/2849/2004/.

Singh, S., Johnson, F. S., and Power, R. A.: Gravity wave seeding of equatorial plasma bubbles, J. Geophys. Res., 102, 7399-7410, 1997a.

Singh, S., Bamgboye, D. K., McClure, J. P., and Johnson, F. S.: Morphology of equatorial plasma bubbles, J. Geophys. Res., 102, 20 019-20 029, 1997b.

Sobral, J. H. A., Abdu, M. A., Takahashi, H., Taylor, M. J., de Paula, E. R., Zamlutti, C. J., de Aquino, M. G., and Borba, G. L.: Ionospheric plasma bubble climatology over Brazil based on 22 years (1977-1998) of $630 \mathrm{~nm}$ airglow observations, J. Atmos. 
Solar Terr. Phys., 64, 1517-1524, 2002.

Stolle, C., Lühr, H., Rother, M., and Balasis, G.: Magnetic signatures of equatorial spread $\mathrm{F}$ as observed by the CHAMP satellite, J. Geophys. Res., 111, A02304, doi:10.1029/2005JA011184, 2006.

Su, S.-Y., Lin, C. H., Ho, H. H., and Chao, C. K.: Distribution characteristics of topside ionospheric density irregularities: Equatorial versus midlatitude regions, J. Geophys. Res., 111, A06305, doi:10.1029/2005JA011330, 2006.
Van Dierendonck, A. J., Hua, Q., and Klobuchar, J.: Ionospheric scintillation monitoring using commercial single frequency C/A code receivers, Proceedings of ION GPS 93, Salt Lake City, UT, 22-24 September, 1333-1342, 1993.

Woodman, R. F. and LaHoz, C.: Radar observations of F region equatorial irregularities, J. Geophys. Res., 81, 5447-5466, 1976. 